\title{
Recovery, Work Engagement, and Proactive Behavior: A New Look at the Interface Between Nonwork and Work
}

\author{
Sabine Sonnentag \\ Technical University of Braunschweig
}

\begin{abstract}
This study examined work-related outcomes of recovery during leisure time. A total of 147 employees completed a questionnaire and a daily survey over a period of 5 consecutive work days. Multilevel analyses showed that day-level recovery was positively related to day-level work engagement and day-level proactive behavior (personal initiative, pursuit of learning) during the subsequent work day. The data suggest considerable daily fluctuations in behavior and attitudes at work, with evidence that these are related to prior experience and opportunity for recovery in the nonwork domain.
\end{abstract}

Life outside work has an impact on how one feels and behaves at work. Well-being and performance at work benefit from positive mood experienced at home (Williams \& Alliger, 1994) and from the absence of conflicts between family and work (Frone, 2000; Kossek \& Ozeki, 1999; Netemeyer, Boles, \& McMurrian, 1996). Moreover, researchers suggested that periods of rest from work are of particular importance for maintaining well-being at work (Eden, 2001; Quick \& Quick, 1984). There is increasing empirical evidence that vacations and other periods of rest result in a decrease in perceived job stress and burnout (Etzion, Eden, \& Lapidot, 1998; Westman \& Eden, 1997; Westman \& Etzion, 2001) and an increase in life satisfaction (Lounsbury \& Hoopes, 1986). Thus, recovery processes that occur during vacations and other breaks bring some relief from negative experiences at work.

However, vacation effects fade out quickly, and well-being deteriorates soon after a person returns to work (Westman \& Eden, 1997; Westman \& Etzion, 2001). This observation suggests that individuals may need additional opportunities for recovery. For example, recovery that occurs in the evening after normal working days or during weekends might be very important for maintaining well-being and performance. In this article, I examine the effects of recovery in the evening after daily work in a regular work week. Specifically, the study investigates the impact of these recovery periods on subsequent work engagement and proactive behavior at work (c.f. Edwards \& Rothbard, 2000). Figure 1 presents the main concepts and the hypothesized relationships to be tested in this study.

\section{Recovery Concept}

Effort expenditure at work draws upon an individual's resources and may cause mood- and performance-related strain reactions

This study was supported by a research grant (12/00) from the University of Konstanz, which is gratefully acknowledged. I thank Verena Friedrich, Anne Rohn, and Sandra Ohly for their help in all tasks related to data collection and Wilmar Schaufeli for helpful comments on an earlier version of this article.

Correspondence concerning this article should be addressed to Sabine Sonnentag, Institute of Psychology, Technical University of Braunschweig, Spielmannstrasse 19, 38092 Braunschweig, Germany. E-mail: s.sonnentag@tu-bs.de
(Repetti, 1993; Totterdell, Spelten, Smith, Barton, \& Folkard, 1995; Zohar, 1999). Recovery is necessary to prevent an ongoing deterioration in mood and performance in the long run (Meijman $\&$ Mulder, 1998). Studies show that recovery is closely related to well-being; insufficiently recovered individuals experience increased levels of burnout (Sluiter, Van der Beek, \& Frings-Dresen, 1999).

\section{Effects of Recovery}

\section{Work Engagement}

Recovery attained during leisure time has an effect on how individuals experience the subsequent work day, and it is crucial for work engagement (see Figure 1). Drawing on earlier work by Kahn (1992; cf. also Kahn, 1990), Schaufeli and his colleagues defined work engagement as a "persistent, positive affectivemotivational state of fulfillment" (Maslach, Schaufeli, \& Leiter, 2001, p. 417; Salanova, Schaufeli, Llorens, Peiro, \& Grau, 2000; Schaufeli, Salanova, Gonzáles-Romá, \& Bakker, 2002).

Work engagement is a concept relevant for employee well-being and work behavior for several reasons. First, work engagement is a positive experience in itself (Schaufeli et al., 2002). Second, it is related to good health and positive work affect (Demerouti, Bakker, de Jonge, Janssen, \& Schaufeli, 2001; Rothbard, 2001). Third, work engagement helps individuals derive benefits from stressful work (Britt, Adler, \& Bartone, 2001). Fourth, work engagement is positively related to organizational commitment (Demerouti et al., 2001) and is expected to affect employee performance (Kahn, 1990)

Past research conceptualized work engagement as a relative stable individual difference variable (Salanova et al., 2000). Nevertheless, it can be assumed that there are daily fluctuations in the experience of work engagement within one person (Kahn, 1990). Experience sampling studies showed substantial intraindividual variations in work-related affective experiences (Fisher, 2000; Teuchmann, Totterdell, \& Parker, 1999). One can also assume that work engagement shows such an intraindividual variation and fluctuates from one day to the other. In other words, work engagement does not differ only between individuals (trait aspect) but also shows within-person variation over time. Based on qualitative 


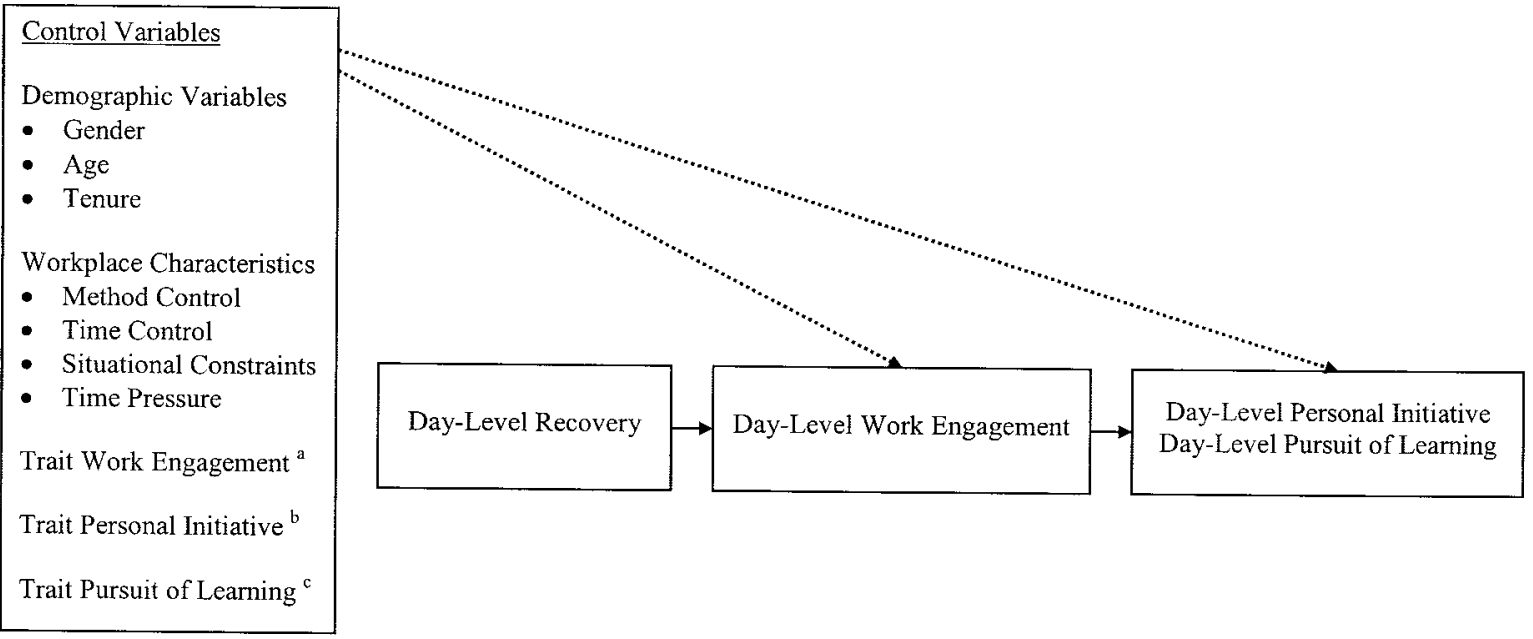

Figure 1. Model of study variables. Solid lines denote hypothesized effects. Dotted lines denote effects of control variables. ${ }^{\mathrm{a} C}$ Controlled for when predicting day-level work engagement. ${ }^{\mathrm{b}}$ Controlled for when predicting day-level personal initiative. ${ }^{\mathrm{c} C o n t r o l l e d ~ f o r ~ w h e n ~ p r e d i c t i n g ~ d a y-l e v e l ~ p u r s u i t ~ o f ~ l e a r n i n g . ~}$

data, Kahn (1990) proposed that physical, emotional, and psychological resources are a necessary prerequisite for engaging at work. This implies that recovery and the associated restoration of resources help individuals experience work engagement.

The basic components of work engagement are vigor, dedication, and absorption (Schaufeli et al., 2002). Recovery will have a positive effect on the experience of vigor. Compared with individuals who have not recovered, recovered individuals will be able and willing to invest effort and to be more resilient when confronted with stressful situations. Experimental research shows that individuals who are not sufficiently recovered from preceding workload feel less vigorous and invest less effort on subsequent tasks (Lorist et al., 2000; Schellekens, Sijtsma, Vegter, \& Meijman, 2000). Moreover, research on shift work indicated that employee alertness tends to increase as the number of rest days passed after the last shift increases (Totterdell et al., 1995).

Recovery will also have a positive effect on dedication. Recovered individuals will have enough resources available to become involved in their work. If insufficiently recovered, individuals will be reluctant to dedicate themselves to work because this will further draw upon their resources (Hobfoll, 1998). Empirical studies show that fatigued and insufficiently recovered individuals tend to withdraw from the demands present at the very moment (Repetti, 1989; Westman \& Etzion, 2001).

Finally, recovery will have a positive effect on absorption. If recovered, individuals are in the state to concentrate fully on the task at hand and to ignore irrelevant cues. Insufficient recovery and residual fatigue will result in greater difficulties in concentrating on the task at hand (Krueger, 1989; Proctor, White, Robins, Echeverria, \& Rocskay, 1996) and in more effortful self-regulatory processes (Zijlstra, 1996). As a consequence, less self-regulatory capacity will be available for concentrating closely on one's tasks and for remaining immersed in them (cf. Baumeister, Bratslavsky, Muraven, \& Tice, 1998). Taken together, recovery is important for experiencing vigor, dedication, and absorption, that is, for showing work engagement.
Hypothesis 1: Recovery will have a positive effect on work engagement.

\section{Proactive Behavior}

Recovery will also have an effect on work behavior, particularly proactive behavior. Crant (2000) defined proactive behavior as "taking initiative in improving current circumstances or creating new ones; it involves challenging the status quo rather than passively adapting to present conditions" (p. 436). Proactive behavior implies an active approach toward work (Frese, Kring, Soose, \& Zempel, 1996; Parker, 2000) and aims at improving given work methods and procedures as well as developing personal prerequisites for meeting future work demands. It comprises behaviors such as personal initiative (Frese et al., 1996) and taking charge (Morrison \& Phelps, 1999) and is closely related to flexible role orientations (Parker, Wall, \& Jackson, 1997). Proactive behavior also includes the active search for learning opportunities and engagement in learning activities (Frese et al., 1996; London \& Mone, 1999). Often, proactive behavior is discretionary in nature (Frese et al., 1996; Morrison \& Phelps, 1999).

Proactive behavior is crucial in modern organizations characterized by fast changes and reduced supervision. To show flexibility, to meet customer demands, and to compete in the global economy, organizations need employees who go beyond narrow task requirements and who approach work proactively by taking initiative and actively pursuing learning (Crant, 2000; Frese et al., 1996; Parker, 2000).

Past research has conceptualized proactivity as a relatively stable individual disposition toward proactive behavior (Bateman \& Crant, 1993). More recent research shows that proactive orientations and behaviors are additionally predicted by workplace factors and organizational variables (Fay \& Frese, 2001; Morrison \& Phelps, 1999; Parker et al., 1997). These findings imply that proactivity includes a situational component and is not a completely stable trait. Additionally, I suggest that there is intraindi- 
vidual variability in proactive behavior across time. An individual's state of recovery on a specific day will have a positive effect on this person's proactive behavior on that day. This effect will be mediated by work engagement (see Figure 1).

There are several reasons why recovery should affect proactive behavior via work engagement. First, it requires additional effort to start proactive behavior and to persist in it (Frese, Fay, Hilburger, Leng, \& Tag, 1997). When recovered, an individual has enough resources available to spend this extra effort. Feelings of vigor will be particularly helpful here. When insufficiently recovered, the individual will be reluctant to spend the additional effort. Second, because recovered individuals feel more vigorous, they can accomplish their in-role tasks with less effort (Hockey, 2000). Resources are left to be spent on proactive behavior. Because proactive behaviors are often discretionary, there is little need for individuals to start them when they are in a suboptimal state and do not have enough resources available. Third, for individuals to engage in proactive behavior, it is necessary for them to care about their work and to regard it as worthwhile to invest the extra effort. When dedicated to their work and enthusiastic about it, individuals will be more likely engage in proactive actions to keep the work situation a positive one and to further improve it. Fourth, to perceive opportunities for proactive behavior and to persist in it, it is important for individuals to become absorbed in their work and to concentrate on it. It is crucial for them to resist the temptation to detach from work in the case of emerging difficulties. Feeling recovered will help individuals to immerse in their work, to concentrate on it, and-as a consequence-to show proactive behavior.

Proactive behavior will benefit from recovery. Individuals will show more proactive behavior on days in which they feel recovered than on days in which they do not feel sufficiently recovered. Work engagement plays a crucial role in mediating the effect of recovery on proactive behavior.

Hypothesis 2: Recovery will have a positive effect on proactive behavior.

Hypothesis 3: The effect of recovery on proactive behavior will be mediated by work engagement.

\section{Rationale of the Study}

The study was based on a within-person design and examined whether recovery during leisure time on a specific day has an impact on work engagement and proactive behavior during the subsequent work day. When investigating the effects of recovery on work engagement and proactive behavior, one has to take into account that additional factors might impact on these variables. Studies have shown that job characteristics, such as job control and job demands, are related to recovery as well as to work engagement and proactive behavior (Demerouti et al., 2001; Fay \& Frese, 2001; Parker et al., 1997; Sluiter, Frings-Dresen, van der Beek, \& Meijman, 2001). This implies that a relationship between recovery on the one hand and work engagement and proactive behavior on the other hand might be caused by job characteristics as third variables. To rule out this alternative interpretation, this study controlled for job characteristics in the analyses.
In addition, an individual's work engagement on a specific day may not be the result of only the day-specific level of recovery. The individual's general tendency to show work engagement may also affect work engagement during this specific day. The same applies for proactive behavior: Proactive behavior on a specific day may be substantially influenced by the individual's general tendency to show proactive behavior. To test the effect of recovery beyond and above the effects of the trait aspects of work engagement and proactivity respectively, I included these trait aspects as control variables in the analyses. Figure 1 gives an overview of all control variables included in the study.

\section{Method \\ Sample}

Employees of six public service organizations participated in the study. Main organizational tasks included a broad range of administrative tasks (e.g., administration of justice, administration of real estate) as well as services in the public security domain. Site managers at the organizations were approached, and they were informed about the study. After managers expressed consent to participate, 425 survey packages were sent to potential respondents. Survey packages included an information letter, a questionnaire, daily survey material, and a stamped return envelope preaddressed to the researcher at the university. The information letter introduced the study as research on "stress and recovery" and emphasized voluntariness, anonymity, and confidentiality of responses. To encourage participation, organization-specific feedback about study variables was promised and was later presented to the participating organizations.

A total of 147 employees returned useable questionnaires and daily surveys, which represents an overall response rate of $34.6 \%$ (response rates for the six organizations ranged between $17 \%$ and $60 \%$ ). The number of participants in the six organizations were 4, 10, 24, 24, 25, and 60 persons, respectively. In the total sample, $65 \%$ of the respondents were men, and $35 \%$ were women. Average age was 39 years $(S D=9.9)$. Participants' work experience ranged between 1 and 42 years $(M=18.5)$. Twenty-nine percent of the participants had a supervisory job. Twenty-eight percent of the participants had completed a 2- to 3-year professional training, 7\% had completed a 2- to 3-year professional training and additionally held an advanced professional degree, $42 \%$ had completed a 2 - to 3 -year specific civil service training, and $22 \%$ had a university degree.

\section{Measures}

Data were collected by a questionnaire and a daily survey. Participants were instructed to complete the questionnaire before they started to fill in the daily survey. All items were in German.

\section{Questionnaire Data}

The questionnaire assessed job characteristics, trait work engagement, trait proactive behavior, and demographic variables. These variables were control variables in the analyses.

Job characteristics. Four scales developed by Semmer (1984) and Zapf (1993) were used to measure job characteristics. These scales are widely used in German-speaking countries (Frese, 1985; Garst, Frese, \& Molenaar, 2000; Semmer, Zapf, \& Greif, 1996) and show acceptable-togood validity coefficients (for a summary, cf. Semmer, Zapf, \& Dunckel, 1999). Specifically, job control was assessed with two scales that measure method control and time control, and job demands were assessed with two scales that measure situational constraints and time pressure. The method 
control measure consisted of five items that referred to the degree an individual can influence the way and methods of doing his or her job (sample item: "Can you influence the way of how you accomplish your tasks?"; Cronbach's $\alpha=.75$ ). Time control was assessed with five items that referred to the possibility of influencing time aspects of one's job (sample item: "To what degree can you influence the pace of your work"; Cronbach's $\alpha=.71$ ). Situational constraints were assessed with five items that referred to problems caused by missing or defective equipment and tools or by missing or outdated information (Cronbach's $\alpha=.74$ ). Time pressure was measured with five items that referred to a high quantitative work load (sample item: "How often do you work under time pressure?"; Cronbach's $\alpha=.86$ )

Trait work engagement. The trait aspect of work engagement was measured with 16 items from the Utrecht Work Enthusiasm Scale (UWES) developed by Schaufeli et al. (2002). These items cover three aspects of the work engagement concept: vigor (sample item: "I feel strong and vigorous in my work"), dedication (sample item: "I am enthusiastic about my job"), and absorption (sample item: "I get carried away by my work"). Participants answered the items on a 7-point frequency rating scale, ranging from $1=$ never to $7=$ every day (instead of 0 to 6 in the original version of the UWES). Schaufeli et al. (2002) suggested that vigor, dedication, and absorption represent three distinct dimensions of work engagement. A principal component analysis conducted with the data from the present study did not result in a clear factor solution. Therefore, an overall scale was used that showed high reliability (Cronbach's $\alpha=.91$ ).

Trait proactive behavior. Two aspects of trait proactive behavior were measured: trait personal initiative and trait pursuit of learning. Trait personal initiative was assessed with the 7-item scale developed by Frese et al. (1997). Participants responded to a 5-point rating scale ranging from $1=$ not true at all to 5 = very true (sample item: "I actively attack problems"; Cronbach's $\alpha=.84$ ). Trait pursuit of learning was assessed with five items from the learning goal orientation scale developed by VandeWalle (1997). This scale measures an individual's preference for challenging tasks that offer the opportunity for learning. Five-point rating scales were used, ranging from $1=$ not true at all to $5=$ very true (sample item: "I often look for opportunities to develop new skills and knowledge"; Cronbach's $\alpha=.86$ ).

Other variables. As additional control variables, one-item measures assessed gender, age, and tenure.

\section{Daily Survey Data}

The daily survey assessed day-level measures of recovery, work engagement, and proactive behavior. Whereas the trait measures of work engagement, personal initiative, and pursuit of learning assessed in the questionnaire refer to a person's general level of work engagement, personal initiative, and pursuit of learning, day-level measures assessed in the daily survey refer to a person's level of work engagement, personal initiative, and pursuit of learning on a specific day. Participants completed the daily survey over a period of 5 consecutive work days. For each day, the daily survey comprised a section to be filled in at the beginning of the work day and a section to be filled in at the end of the work day. Participants responded to all day-level measures on a 5-point Likert scale $(1=$ not true at all to $5=$ very true).

Day-level recovery. In the mornings of all 5 data collection days, participants reported their level of recovery before starting to work. Specifically, participants responded to three items that linked feelings of recovery to leisure time activities: (a) Because of the leisure activities pursued yesterday, I feel recovered. (b) Because of the leisure activities pursued yesterday, I feel relaxed. (c) Because of the leisure activities pursued yesterday, I am in a good mood. Cronbach's alphas were computed separately for the 5 days. They ranged between .92 and $.93(M=.92)$.

Day-level work engagement. At the end of each work day before leaving the workplace, participants indicated their level of work engage- ment during this past work day. Specifically, they responded to 16 items from the UWES (Schaufeli et al., 2002). To assess work engagement on a specific work day (as opposed to the general frequency to experience work engagement), I instructed participants to answer the items with respect to the past work day. Because the frequency rating used in the trait measurement was not applicable to the day-level measurement, participants provided an intensity rating.

I used an overall scale of day-level work engagement that included items that referred to vigor (sample item: "I felt strong and vigorous in my work"), dedication (sample item: "I was enthusiastic about my job"), and absorption on that specific day (sample item: "Today, I got carried away by my work"). Cronbach's alphas computed separately for each of the 5 days ranged between .89 and $.93(M=.91)$.

Day-level proactive behavior. The daily survey assessed two aspects of day-level proactive behavior on 5 days: day-level personal initiative and day-level pursuit of learning. Again, participants were instructed to answer the items with respect to the past work day. Day-level personal initiative was measured with seven items adopted from the personal initiative measure developed by Frese et al. (1997; sample item: "Today, I attacked a problem actively"). Cronbach's alphas that were computed separately for each day ranged between .67 and $.89(M=.79)$. Day-level pursuit of learning was measured with five items adopted from VandeWalle's (1997) learning goal orientation scale (sample item: "Today I actually looked for opportunities to develop new skills and knowledge"). Cronbach's alphas that were computed separately for each day ranged between .82 and .91 $(M=.87)$

\section{Data Analysis}

Each study participant provided data at the person level (e.g, trait work engagement, demographic variables) and at the day level (e.g., day-level recovery, day-level work engagement). Day-level data were nested within the person-level data. Multilevel analysis, that is, a hierarchical linear modeling approach, was used for analyzing the data (Bryk \& Raudenbush, 1992). For hierarchically structured data sets such as the present one, multilevel analysis is superior to ordinary least square regression analysis, because it does not assume independence of observations but allows for dependent observations within the higher level data structure (Snijders \& Bosker, 1999). With respect to the present study, multilevel analysis takes the dependence of day-level measurements within each person into account.

The MLn computer program was used for data analysis (Rasbash \& Woodhouse, 1996). In these analyses, predictor variables at the person level (trait work engagement, trait proactive behavior, job characteristics, and demographic variables) were Level 2 data and predictor variables at the day level (day-level recovery, day-level work engagement, day-level proactive behavior) were Level 1 data. Person-level predictor variables were centered around the grand mean, and day-level predictor variables were centered around the respective person mean.

\section{Results}

Table 1 shows means, standard deviations, and zero-order correlations between the study variables. When appropriate, both person-level and day-level correlations are displayed. To correlate variables assessed at the person-level with day-level measures of work engagement, personal initiative, and pursuit of learning, I averaged the day-level measures across the 5 days.

\section{Variability of Day-Level Measures Over Time}

Before testing the hypotheses, I examined within-person and between-person variations of the day-level measures across the 5 


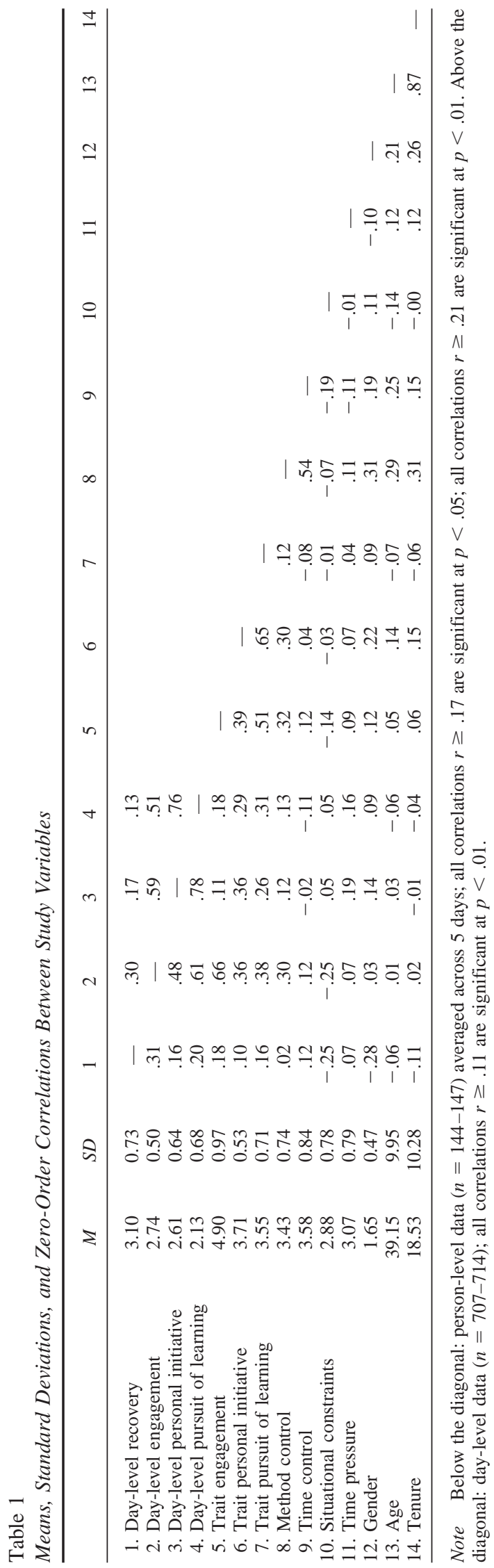

days. One-way analysis of variance (ANOVA) with random effects showed that day-level variance in recovery was 0.8644 and person-level variance was 0.2030 . Thus, $81 \%$ of the total variance in recovery was attributable to within-person variation, and $19 \%$ was attributable to between-person variation. Day-level variance was $42 \%$ for work engagement (computed from the intercept variance; cf. null model displayed in Table 2), $46 \%$ for personal initiative, and $41 \%$ for pursuit of learning (cf. null models in Table 3 and 4).

Taken together, most of the variance for recovery was attributable to within-person variation, which indicates that feelings of recovery differ substantially from one day to the other. For work engagement and proactive behavior, at least $40 \%$ of the variance was attributable to within-person variation, which suggests that work engagement and proactive behavior are not completely stable over time but fluctuate to a certain degree. This finding stresses the importance of searching for predictors of day-level work engagement and day-level proactive behavior.

\section{Test of Hypotheses}

The effects of recovery on work engagement (Hypothesis 1) and proactive behavior (i.e., personal initiative and pursuit of learning; Hypothesis 2) were tested with multilevel models. Dependent variables in these models were day-level work engagement, daylevel personal initiative, and day-level pursuit of learning, respectively. For each of these three dependent variables, three nested models were compared: a null model, Model 1, and Model 2. In the null model, the intercept was the only predictor. Model 1 included all control variables, specifically demographic variables (gender, age, tenure; Level 2), job characteristics (method control, time control, situational constraints, time pressure; Level 2), and the trait component of the respective dependent variable (Level 2). For example, when predicting day-level work engagement, the model included trait work engagement as control variable; when predicting day-level initiative, the model included trait personal initiative as control variable. In Model 2, day-level recovery (Level 1) was entered as the core predictor variable of interest. A significant improvement of Model 2 over Model 1 will indicate support for Hypothesis 1 and Hypothesis 2, respectively. The improvement of each model over the previous one was tested with the difference between the respective likelihood ratios. This difference follows a chi-square distribution (degree of freedom equal to the number of new parameters added to the model).

Hypothesis 1 stated that recovery will have a positive effect on work engagement. Table 2 displays the results. Table 2 shows estimates, standard errors, and $t$ values for all predictor variables in all models. It also displays likelihood ratios of all models and differences in the likelihood ratios between the nested models and intercept variances at the day-level (Level 1) and at the personlevel (Level 2). Model 1 that included all control variables (demographic variables, job characteristics, trait work engagement) was compared to the null model that included only the intercept. Model 1 showed a significant improvement over the null model $(\Delta-2 \times \log =86.76, d f=8, p<.001)$, and trait work engagement was the only, but highly significant, predictor. In Model 2, day-level recovery was entered. Model 2 showed further improvement over Model $1(\Delta-2 \times \log =43.16, d f=1, p<.001)$. The estimate of day-level recovery was highly significant. This indicates that day-level recovery contributed significantly to the pre- 


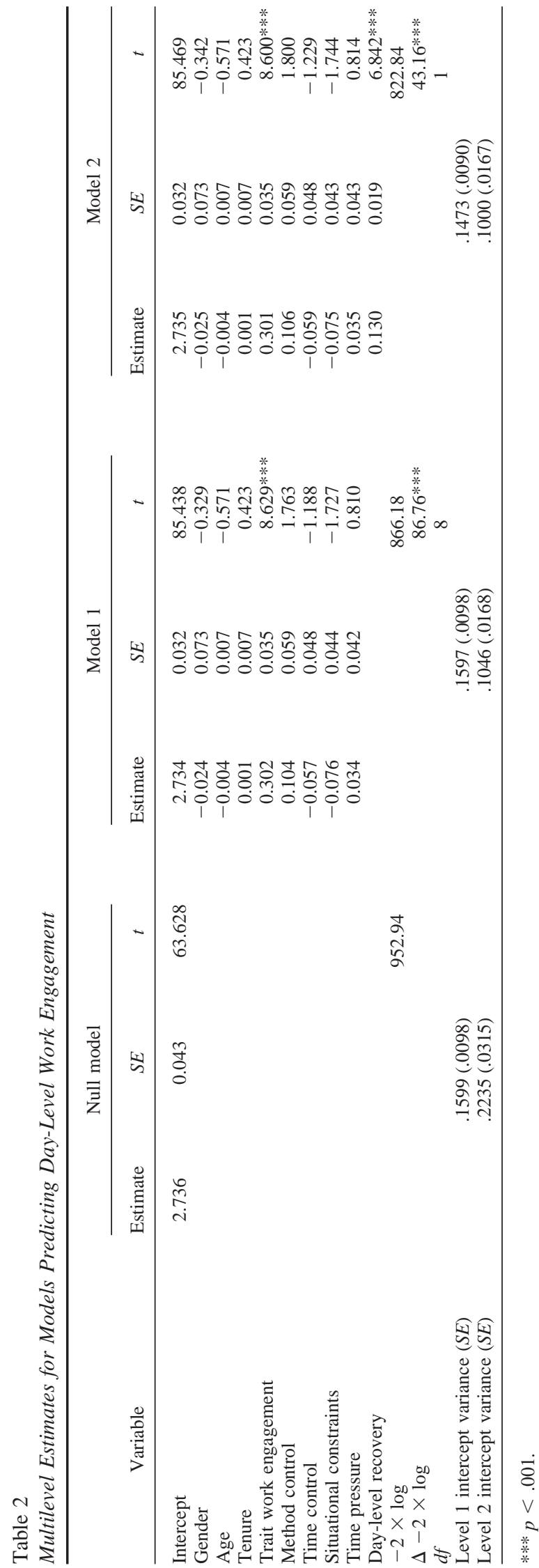

diction of day-level work engagement; its contribution was beyond the effect of trait work engagement. Thus, data supported Hypothesis 1.

Hypothesis 2 stated that recovery will have a positive effect on proactive behavior. Table 3 displays the results for day-level personal initiative as dependent variable. Model 1 that included all control variables (demographic variables, job characteristics, trait personal initiative) showed a better model fit than the null model $(\Delta-2 \times \log =30.95, d f=8, p<.001)$. Trait personal initiative and time pressure were significant predictors; the estimates of both predictors yielded positive signs. After day-level recovery was entered into the model as additional predictor variable (Model 2), model fit further improved $(\Delta-2 \times \log =5.44, d f=1, p<.05)$ and the estimate of day-level recovery turned out to be significant. This indicates that day-level recovery predicted day-level initiative above the effects of trait personal initiative and time pressure.

Similarly, for day-level pursuit of learning as dependent variable, Model 1 that included all control variables (demographic variables, job characteristics, trait pursuit of learning) was compared with the null model (see Table 4). Model 1 fit the data better than the null model $(\Delta-2 \times \log =24.21, d f=8, p<.01)$. The only significant predictor was trait pursuit of learning. After daylevel recovery was entered into the model (Model 2), model fit further improved $(\Delta-2 \times \log =6.68, d f=1, p<.01)$. Day-level recovery emerged as a significant predictor. This finding indicates that day-level recovery predicted day-level pursuit of learning above the effect of trait pursuit of learning. Hypothesis 2 was supported by the data.

Hypothesis 3 stated that the effect of recovery on proactive behavior will be mediated by work engagement. This hypothesis was tested with two procedures: (a) Baron and Kenny's (1986) approach for testing mediator effects, and (b) a direct significance test of the mediating variable effect (MacKinnon \& Dwyer, 1993).

Baron and Kenny (1986) specified that three conditions need to be met to establish mediation: First, the presumed independent variable (day-level recovery) accounts for variation in the presumed mediator (day-level work engagement). Second, the presumed mediator (day-level work engagement) accounts for variation in the presumed dependent variable (day-level proactive behavior). Third, a previously significant relationship between the independent variable (day-level recovery) and the dependent variable (day-level proactive behavior) is no longer significant when controlling for the mediator (day-level work engagement). As the test of Hypothesis 1 showed, the first condition was met. Additional analyses showed that the second condition was also met: Day-level work engagement was a significant predictor of daylevel personal initiative $(\gamma=0.749, S E=.051) t=14.69, p<$ .001 , and of day-level pursuit of learning $(\gamma=0.760, S E=.049)$ $t=15.51, p<.001 .^{1}$

To test the third condition for day-level personal initiative as dependent variable, day-level work engagement was added to all control variables and to day-level recovery in the multilevel model. Model 3 in Table 2 shows the multilevel estimates resulting from this analysis. After day-level work engagement was entered, daylevel recovery was no longer a significant predictor of day-level personal initiative. The estimate of day-level work engagement

\footnotetext{
${ }^{1}$ The complete table is available from Sabine Sonnentag on request.
} 


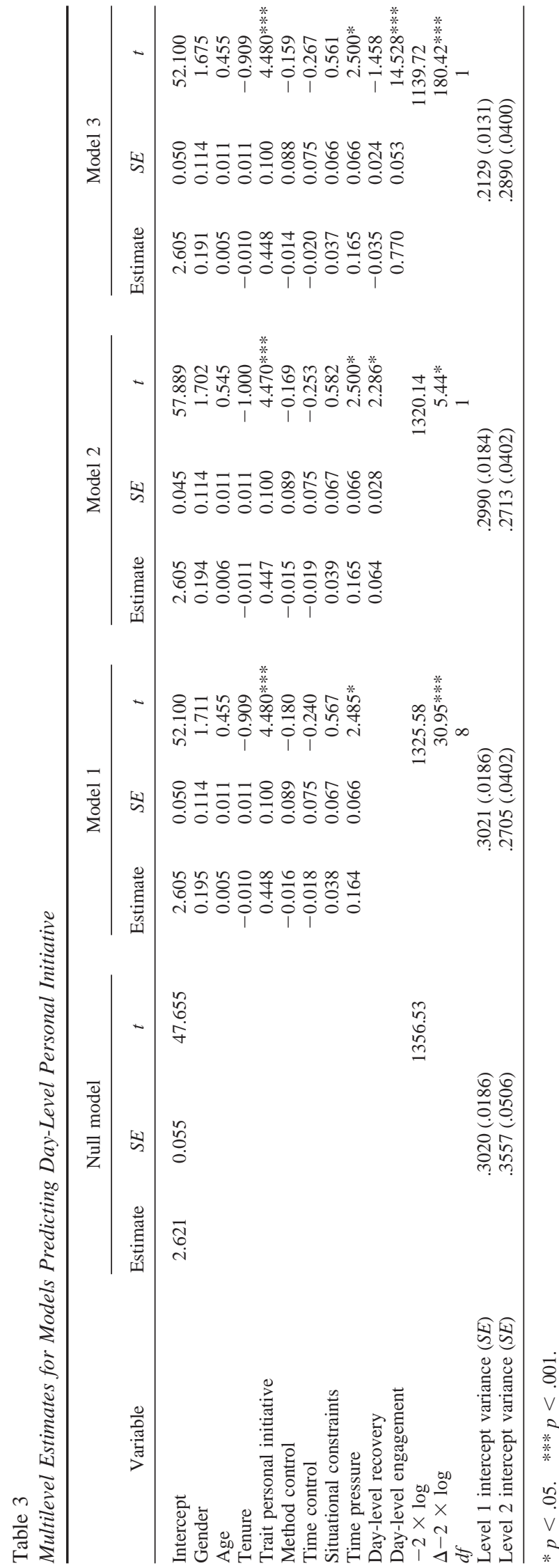

was significant. The same procedure was followed for day-level pursuit of learning as dependent variable. Model 3 in Table 4 displays the results. After day-level work engagement was entered, day-level recovery was no longer a significant predictor of daylevel pursuit of learning. The estimate of day-level work engagement was significant. Analysis following Baron and Kenny's (1986) approach shows that work engagement is a mediator in the relationship between recovery and personal initiative and between recovery and pursuit of learning.

MacKinnon and Dwyer (1993) proposed a more direct test of mediation that is also applicable to multilevel data sets (Krull \& MacKinnon, 1999, 2001). Analysis following this approach resulted in an estimate of $\beta_{\mathrm{a}} \times \beta_{\mathrm{b}}=0.09998$ and a standard error of $\sigma_{\beta_{\mathrm{a}} \beta_{\mathrm{b}}}=0.01636$ for day-level personal initiative as dependent variable. The resulting $z$ statistic was highly significant $(z=6.11$, $p<.001$ ), which indicates that day-level work engagement was a significant mediator in the relationship between day-level recovery and day-level personal initiative. For day-level pursuit of learning as dependent variable, a similar result emerged with $\beta_{\mathrm{a}} \times \beta_{\mathrm{b}}=$ 0.10104 and $\sigma_{\beta_{\mathrm{a}} \beta_{\mathrm{b}}}=0.01644$. Again, the $z$ statistic was highly significant $(z=6.15, p<.001)$. Taken together, this more direct method for testing mediation confirmed the results attained by Baron and Kenny's (1986) method. Both methods showed that the effect of day-level recovery on day-level proactive behavior is mediated by day-level work engagement.

\section{Additional Analyses}

Researchers have suggested that there is an effect not only of nonwork on work experiences but also of work on nonwork experiences (cf. Edwards \& Rothbard, 2000). In the context of the present study, this implies that work engagement and proactive behavior shown on a specific work day might have an effect on recovery during leisure time. An additional analysis tested this assumption. Day-level recovery (measured in the morning of Day $\mathrm{d}+1$ ) was the dependent variable and day-level work engagement, day-level personal initiative, and day-level pursuit of learning (all measured at Day d) were the predictor variables. Again, three nested models were compared (null model, Model 1, and Model 2). Model 1 that included demographic variables (gender, age, tenure) and job characteristics (method control, time control, situational constraints, time pressure) as control variables showed a significant improvement over the null model that only included the intercept $(\Delta-2 \times \log =26.771, d f=7, p<.001)$. The estimates of gender $(\gamma=-0.457, S E=0.131), t=3.489, p<.001$, and situational constraints $(\gamma=-0.194, S E=0.077), t=2.519, p<$ .05 , were significant, which indicates that men and persons experiencing a high degree of situational constraints at work felt less recovered. Model 2 that included day-level work engagement, day-level personal initiative, and day-level pursuit of learning as predictor variables did not show a significant improvement over Model $1(\Delta-2 \times \log =2.21, d f=3, n s)$. This finding indicates that gender and situational constraints at work, but not work engagement or proactive behavior shown on the preceding work day, were related to a person's feelings of recovery in the following morning. Thus, these results do not speak for an effect of work engagement or proactive behavior on recovery.

Response rates in the six participating organizations were moderate, ranging from $17 \%$ to $60 \%$. To test whether response rate had 


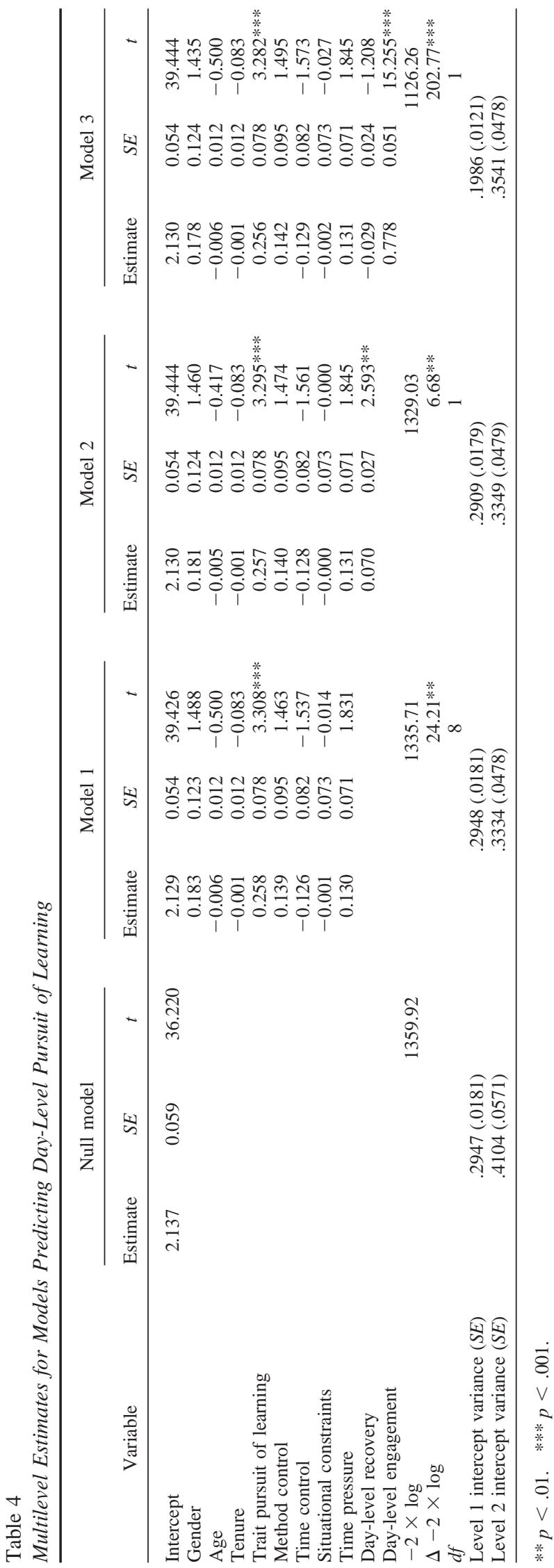

affected the study findings, I conducted an additional analysis that made use of the differences in response rates between organizations. Specifically, the organization-specific response rate was conceptualized as a predictor at an additional (i.e., organizational) level (Level 3). Thus, person-level data (Level 2) were conceptualized as being nested within organizational-level data (Level 3). For predicting day-level work engagement, day-level personal initiative, and day-level pursuit of learning, an additional set of models was tested with organization-specific response rates and interactions between organization-specific response rates and day-level recovery as predictors in addition to all variables entered in Model 2.

Analyses revealed that neither the organization-specific response rate nor the interaction between the organization-specific response rate and day-level recovery were significant predictors of day-level work engagement, day-level personal initiative, or daylevel pursuit of learning. Thus, these findings suggest that response rate did not affect the study findings.

\section{Discussion}

This study provides support for a positive effect of recovery on work engagement and proactive behavior, with work engagement mediating the effects of recovery on proactive behavior. Individuals who feel that they sufficiently recover during leisure time experience a higher level of work engagement during the subsequent work day. This high level of work engagement in turn helps them in taking initiative and pursuing learning goals.

Demographic variables, job characteristics, and the trait aspects of work engagement and proactive behavior have been included as control variables in the analyses. This implies that interpretations that refer to these factors as third variables can be ruled out. Most important, the effects of recovery on work engagement and proactive behavior exist above and beyond the very strong effects of trait work engagement and trait proactive behavior. Thus, it is not only an individual's general tendency to experience work engagement or to take initiative but also this person's degree of recovery that accounts for feelings of work engagement and actions of initiative on a specific day.

Additionally, time pressure turned out to be a positive predictor of day-level initiative. At a first glance, this finding is surprising because one might assume that time pressure impedes extra-role performance. However, a longitudinal study by Fay and Sonnentag (2002) points in a similar direction. Individuals who experienced high levels of time pressure reported more personal initiative. Fay and Sonnentag offered a control theory interpretation for this finding: Stressors such as time pressure point at suboptimal aspects of the work situation and at a need for change to which personal initiative is an adequate response.

Additional analyses showed that men and persons who experience a high degree of situational constraints at work report lower levels of recovery. The finding on situational constraints is in line with previous research that showed that persons who face stressful work need more time to unwind and recover from work (Frankenhaeuser, 1981; Meijman, Mulder, \& Van Dormolen, 1992). Men's low recovery level is surprising at first glance. Because women face a greater total workload than men (Lundberg, Marberg, \& Frankenhaeuser, 1994), one would expect that women have less time and opportunities to recover after work. However, it seems that the picture is more complex. In the present sample, men had 
significantly more children than women, and the number of children was negatively related to day-level recovery. This might imply that in the present sample women had better conditions for recovery. In addition, past research has shown that men experience lower work positive affect and higher work negative affect (Rothbard, 2001) and spend more time on work-related activities during leisure time (Sonnentag, 2001). This implies that men need more time to recover from work but at the same time continue to engage in work-related activities that do not support recovery processes. As a consequence, men end up less recovered than women. Here, clearly more research is needed.

Previous research on respites has shown that the positive effects of vacations are limited and fade out quickly (Westman \& Eden, 1997; Westman \& Etzion, 2001). The present findings illustrate that individuals benefit from shorter rest periods that occur in the evening of normal work weeks. This implies that individuals do not have to postpone all the necessary recovery processes until the time has come for longer rest periods (e.g., vacations). Rather, it seems that daily recovery from work stress is helpful to supplement the effects of vacations. It would be an interesting question for future research to examine whether sufficient recovery after normal work days can prolong the positive effects of vacations.

This article showed an effect of recovery on work engagement and proactive behavior. However, work engagement and proactive behavior might also impact recovery. To rule out this and other alternative causal interpretations (cf. Cook \& Campbell, 1979), day-level recovery was assessed before work engagement and proactive behavior was measured. This study controlled for third variables (particularly the trait aspect of the respective dependent variables) that potentially impacted on the predictor and dependent variables. Finally, reverse causation was tested. There was no evidence for third variables explanations or reverse causation. Thus, although it is difficult to arrive at final conclusions about causality in nonexperimental studies, data speak for an effect of recovery on work engagement and proactive behavior. This interpretation does not exclude the possibility that other work experiences or job situation variables might have an effect on recovery processes. For example, situational constraints turned out to be a significant predictor of low recovery. To develop a deeper understanding of the interplay between work and nonwork, future studies should examine the reciprocal influences in more detail. Also, the question of both negative and positive effects deserves more attention.

\section{Limitations}

This study has some limitations. First, one might be concerned about the use of self-report measures and associated problems of social desirability. However, data were collected anonymously, and study participants were assured of confidentiality. In addition, trait measures of work engagement and proactive behavior were used as control variables. If participants had given highly social desirable answers, these trait measures would have been affected. By controlling for the trait aspects, this study has also controlled for a hypothetical social desirability bias. To overcome problems associated with self-report measures, future studies might collect peer or supervisory ratings of proactive behavior. To assess a person's level of recovery, one might include observations provided by the spouse.
Second, the recovery measure used in this study is not without problems. The items include double statements by connecting feelings of recovery, relaxation, and good mood to leisure-time activities pursued the day before. This might have left respondents with insufficient response options when they felt recovered due to reasons other than their leisure-time activities. Thus, future studies should use distinct measures for assessing a person's level of recovery and the possible causes for recovery.

A third limitation is this study's overall response rate of $34.6 \%$. One possible reason for this moderate response rate is the extensive data collection procedure that asked for more time and effort from study participants than do more simple survey studies. Analyses reported in this article showed that organization-specific response rates were not related to any of the main dependent variables. No interaction effect was found between organizationspecific response rates and the core predictor variable (i.e., daylevel recovery). These findings speak against an effect of response rate on study findings. Results from a recent meta-analysis point in the same direction (Schalm \& Kelloway, 2001). Therefore, it is not very likely that this study's response rate biased the pattern of results reported in this article.

Another limitation of this study is related to the data collection procedure. Although participants received a clear instruction to complete the questionnaire before starting the daily survey, some participants might have first filled in the daily survey. Future research could overcome this problem by using electronic devices (e.g., handheld computers) that allow the exact time to be recorded when specific items are answered.

\section{Implications for Research and Practice}

This study confirms the notion that experiences outside work are crucial for feelings and behavior at work (Netemeyer et al., 1996; Williams \& Alliger, 1994). Moreover, the study has shown that specific experiences that differ from day to day predict what happens at work on a day-to-day basis. However, this study does not provide an answer to the question about the preconditions of successful recovery on a specific day. A recent study that examined daily recovery processes with a different sample suggests that individuals benefit both from active and passive leisure-time activities, whereas the performance of work-related activities at home is detrimental for recovery (Sonnentag, 2001). In a broader context, recovery may be conceptualized as an outcome of nonwork engagement (cf. Rothbard, 2001). Based on previous theorizing on recovery (Meijman \& Mulder, 1998), one can assume that a high level of nonwork engagement is positively related to recovery when nonwork engagement draws on resources other than those needed at work. However, when nonwork engagement draws on the same resources as does work, a high level of nonwork engagement will be negatively related to recovery. Here, more research is needed.

This study focused on the main effects of recovery on work engagement and proactive behavior. In future research, it would be interesting to look at factors that moderate the relationship between recovery and work engagement or proactive behavior. For example, job involvement might be one of the variables that attenuate the effect of recovery on work engagement and proactive behavior. Such a moderator effect would imply that work engagement and proactive behavior would not deteriorate in the case of 
insufficient recovery if a person experiences a high degree of job involvement. Also, amount and quality of sleep are probably important. In addition to a direct effect, there might be an interaction effect of sleep with leisure-time activities on feelings of recovery. Insufficient sleep at night might counteract the positive effects of recovery that occurred during evening leisure time, whereas a good night's sleep might compensate for a lack of recovery during evening time. Therefore, future studies should include measures of sleep.

This study concentrated on short-term effects of recovery. An important question to be addressed in future research refers to long-term effects of recovery. For example, what happens if an individual does not recover sufficiently over a period of several weeks or even months? One might speculate that such a lack of recovery severely threatens an individual's health and well-being (Hobfoll, 1998; Meijman \& Mulder, 1998).

With respect to practical implications, this study suggests that individuals should pay attention to recovery issues. When not recovering sufficiently, individuals may not only miss a pleasant experience but they may also start the next working day in a suboptimal state, which would hinder full work engagement and proactive behavior. Recovery might be particularly helpful after extremely stressful working days and when high work demands are anticipated. Organizations and communities could support recovery processes by providing facilities and by rethinking work time arrangements. In this context, the reduction of extensive overtime is an issue.

The study illustrated that work engagement and proactive behavior benefit from recovery that occurs during leisure time. Given the high relevance of proactive behavior in today's work organizations (Crant, 2000; Frese \& Fay, 2001; Parker, 2000), the present findings have implications for organizations as a whole. An individual's general tendency to show initiative or to pursue learning, along with the respective predictors (Fay \& Frese, 2001; London $\&$ Mone, 1999), is important to ensure high levels of proactive behavior. The individual's level of recovery attained during leisure time also has an effect on this behavior. Thus, to achieve competitive advantage through their employees' proactivity, organizations should encourage their employees to spend their leisure time in a way that allows for sufficient recovery.

\section{References}

Baron, R. M., \& Kenny, D. A. (1986). The moderator-mediator variable distinction in social psychological research: Conceptual, strategic and statistical considerations. Journal of Personality and Social Psychology, 51, 1173-1182.

Bateman, T., \& Crant, J. M. (1993). The proactive component of organizational behavior: A measure and correlates. Journal of Organizational Behavior, 14, 103-118.

Baumeister, R. F., Bratslavsky, E., Muraven, M., \& Tice, D. M. (1998). Ego depletion: Is the active self a limited resource? Journal of Personality and Social Psychology, 74, 1252-1265.

Britt, T. W., Adler, A. B., \& Bartone, P. T. (2001). Deriving benefits from stressful events: The role of engagement in meaningful work and hardiness. Journal of Occupational Health Psychology, 6, 53-63.

Bryk, A. S., \& Raudenbush, S. W. (1992). Hierarchical linear models Application and data analysis methods. Newbury Park, CA: Sage.

Cook, T. D., \& Campbell, D. T. (1979). Quasi-experimentation. Design and analysis for field settings. Boston: Houghton Mifflin.
Crant, J. M. (2000). Proactive behavior in organizations. Journal of Management, 26, 435-462.

Demerouti, E., Bakker, A. B., de Jonge, J., Janssen, P. P. M., \& Schaufeli, W. B. (2001). Burnout and engagement at work as a function of demands and control. Scandinavian Journal of Work Environment and Health, 27, 279-286.

Eden, D. (2001). Vacations and other respites: Studying stress on and off the job. In C. L. Cooper \& I. T. Robertson (Eds.), International review of industrial and organizational psychology (pp. 121-146). Chichester, England: Wiley.

Edwards, J. R., \& Rothbard, N. P. (2000). Mechanisms linking work and family: Clarifying the relationship between work and family constructs. Academy of Management Journal, 25, 178-199.

Etzion, D., Eden, D., \& Lapidot, Y. (1998). Relief from job stressors and burnout: Reserve service as a respite. Journal of Applied Psychology, 83, 577-585.

Fay, D., \& Frese, M. (2001). The concepts of personal initiative (PI): An overview of validity studies. Human Performance, 14, 97-124.

Fay, D., \& Sonnentag, S. (2002). Rethinking the effects of stressors: A longitudinal study on personal initiative. Journal of Occupational Health Psychology, 7, 221-234.

Fisher, C. D. (2000). Mood and emotions while working: Missing pieces of job satisfaction? Journal of Organizational Behavior, 21, 185-202.

Frankenhaeuser, M. (1981). Coping with stress at work. International Journal of Health Services, 11, 491-510.

Frese, M. (1985). Stress at work and psychosomatic complaints: A causal interpretation. Journal of Applied Psychology, 70, 314-328.

Frese, M., \& Fay, D. (2001). Personal initiative: An active performance concept for work in the 21 st century. In B. M. Staw \& R. L. Sutton (Eds.), Reserach in organizational behavior (Vol. 23, pp. 133-187). Stamford, CT: JAI Press.

Frese, M., Fay, D., Hilburger, T., Leng, K., \& Tag, A. (1997). The concept of personal initiative: Operationalization, reliability and validity in two German samples. Journal of Occupational and Organizational Psychology, 70, 139-161.

Frese, M., Kring, W., Soose, A., \& Zempel, J. (1996). Personal initiative at work: Differences between East and West Germany. Academy of Management Journal, 39, 37-63.

Frone, M. R. (2000). Work-family conflict and employee psychiatric discorders: The national comorbidity survey. Journal of Applied Psychology, 85, 888-895.

Garst, H., Frese, M., \& Molenaar, P. C. M. (2000). The temporal factor of change in stressor-strain relationships: A growth curve model on a longitudinal study in East Germany. Journal of Applied Psychology, 85, 417-438.

Hobfoll, S. E. (1998). Stress, culture, and community The psychology and physiology of stress. New York: Plenum.

Hockey, G. R. J. (2000). Work environments and performance. In N. Chmiel (Ed.), Work and organizational psychology a European perspective (pp. 206-230). Oxford, England: Basil Blackwell.

Kahn, W. A. (1990). Psychological conditions of personal engagement and disengagement at work. Academy of Management Journal, 33, 692-724.

Kahn, W. A. (1992). To be fully there: Psychological presence at work. Human Relations, 45, 321-349.

Kossek, E. E., \& Ozeki, C. (1999). Bridging the work family policy and productivity gap: A literature review. Community, Work \& Family, 2, 7-32.

Krueger, G. P. (1989). Sustained work, fatigue, sleep loss and performance: A review of the issues. Work \& Stress, 3, 129-141.

Krull, J. L., \& MacKinnon, D. P. (1999). Multilevel mediation modeling in group-based intervention studies. Evaluation Review, 23, 418-444.

Krull, J. L., \& MacKinnon, D. P. (2001). Multilevel modeling of individual and group level mediated effects. Multivariate Behavioral Reserach, 36, 249-277. 
London, M., \& Mone, E. M. (1999). Continuous learning. In D. R. Ilgen \& E. D. Pulakos (Eds.), The changing nature of performance. Implications for staffing, motivation, and development (pp. 119-153). San Francisco, CA: Jossey-Bass.

Lorist, M. M., Klein, M., Nieuwenhuis, S., de Jong, R., Mulder, G., \& Meijman, T. F. (2000). Mental fatigue and task control: Planning and preparation. Psychophysiology, 37, 614-625.

Lounsbury, J. W., \& Hoopes, L. L. (1986). A vacation from work: Chances in work and nonwork outcomes. Journal of Applied Psychology, 71, 392-401.

Lundberg, U., Marberg, B., \& Frankenhaeuser, M. (1994). The total workload of male and female white collar workers as related to age, occupational level and number of children. Scandinavian Journal of Psychology, 35, 315-327.

MacKinnon, D. P., \& Dwyer, J. H. (1993). Estimating mediated effects in prevention studies. Evaluation Review, 17, 144-158.

Maslach, C., Schaufeli, W. B., \& Leiter, M. P. (2001). Job burnout. Annual Review of Psychology, 52, 397-422.

Meijman, T. F., \& Mulder, G. (1998). Psychological aspects of workload. In P. J. D. Drenth \& H. Thierry (Eds.), Handbook of work and organizational psychology, Vol. 2 Work psychology (pp. 5-33). Hove, England: Psychology Press.

Meijman, T. F., Mulder, G., \& Van Dormolen, M. (1992). Workload of driving examiners: A psychophysiological field study. In H. Kragt (Ed.), Enhancing industrial performances (pp. 245-260). London: Taylor \& Francis.

Morrison, E. W., \& Phelps, C. C. (1999). Taking charge at work: Extrarole efforts to initiate workplace change. Academy of Management Journal, 42, 403-419.

Netemeyer, R. G., Boles, J. S., \& McMurrian, R. (1996). Development and validation of work-family conflict and family-work conflict scales. Journal of Applied Psychology, 81, 400-410.

Parker, S. K. (2000). From passive to proactive motivation: The importance of flexible role orientations and role breadth self-efficacy. Applied Psychology An International Review, 49, 447-469.

Parker, S. K., Wall, T. D., \& Jackson, P. R. (1997). "That's not my job": Developing flexible employee work orientations. Academy of Management Journal, 40, 899-929.

Proctor, S. P., White, R. F., Robins, T. G., Echeverria, D., \& Rocskay, A. Z. (1996). Effect of overtime work on cognitive function in automotive workers. Scandinavian Journal of Work Environment and Health, 22, 124-132.

Quick, J. C., \& Quick, J. D. (1984). Organizational stress and preventive management. New York: McGraw-Hill.

Rasbash, J., \& Woodhouse, G. (1996). MLn. London: University of London, Institute of Education.

Repetti, R. L. (1989). Effects of daily workload on subsequent behavior during marital interaction: The roles of social withdrawal and spouse support. Journal of Personality and Social Psychology, 57, 651-659.

Repetti, R. L. (1993). Short-term effects of occupational stressors on daily mood and health complaints. Health Psychology, 12, 125-131.

Rothbard, N. P. (2001). Enriching or depleting? The dynamics of engagement in work and family roles. Administrative Science Quarterly, 46, $655-684$

Salanova, M., Schaufeli, W. B., Llorens, S., Peiro, J. M., \& Grau, R. (2000). Desde el "burnout" al "engagement": una nueva perspective? [From "burnout" to "engagement": A new perspective?]. Revista de Psicologia del Trabajo y de las Organizaciones, 16, 117-134.

Schalm, R. L., \& Kelloway, E. K. (2001). The relationship between response rate and effect size in occupational health psychology research. Journal of Occupational Health Psychology, 6, 160-163.

Schaufeli, W. B., Salanova, M., Gonzáles-Romá, V., \& Bakker, A. B. (2002). The measurement of engagement and burnout: A two sample confirmatory factor analytic approach. Journal of Happiness Studies, 3, 71-92.

Schellekens, J. M. H., Sijtsma, G. J., Vegter, E., \& Meijman, T. F. (2000). Immediate and delayed after-effects of long lasting mentally demanding work. Biological Psychology, 53, 37-56.

Semmer, N. (1984). Streßbezogene Tätigkeitsanalyse [Stress-oriented analysis task-analysis]. Weinheim, Germany: Beltz.

Semmer, N., Zapf, D., \& Dunckel, H. (1999). Instrument zur Stressbezogenen Tätigkeitsanalyse (ISTA) [Instrument for stress-oriented task analysis (ISTA)]. In H. Dunckel (Ed.), Handbuch psychologischer Arbeitsanalyseverfahren (pp. 179-204). Zürich, Switzerland: vdf Hochschulverlag an der ETH.

Semmer, N., Zapf, D., \& Greif, S. (1996). "Shared job strain": A new approach for assessing the validity of job stress measurements. Journal of Occupational and Organizational Psychology, 69, 293-310.

Sluiter, J. K., Frings-Dresen, M. H. W., van der Beek, A. J., \& Meijman, T. F. (2001). The relation between work-induced neuroendocrine reactivity and recovery, subjective need for recovery, and health status. Journal of Psychosomatic Research, 50, 29-37.

Sluiter, J. K., Van der Beek, A. J., \& Frings-Dresen, M. H. W. (1999). The influence of work characteristics on the need for recovery and experienced health: A study on coach drivers. Ergonomics, 42, 573-583.

Snijders, T. A. B., \& Bosker, R. J. (1999). Multilevel analysis. An introduction to basic and advanced multilevel modeling. London: Sage.

Sonnentag, S. (2001). Work, recovery activities, and individual well-being: A diary study. Journal of Occupational Health Psychology, 6, 196-210.

Teuchmann, K., Totterdell, P., \& Parker, S. K. (1999). Rushed, unhappy, and drained: An experience sampling study of relations between time pressure, perceived control, mood, and emotional exhaustion in a group of accountants. Journal of Occupational Health Psychology, 4, 37-54.

Totterdell, P., Spelten, E., Smith, L., Barton, J., \& Folkard, S. (1995). Recovery from work shifts: How long does it take? Journal of Applied Psychology, 80, 43-57.

VandeWalle, D. (1997). Development and validation of a work domain goal orientation instrument. Educational and Psychological Measure ment, 57, 995-1015.

Westman, M., \& Eden, D. (1997). Effects of a respite from work on burnout: Vacation relief and fade-out. Journal of Applied Psychology, 82, 516-527.

Westman, M., \& Etzion, D. (2001). The impact of vacation and job stress on burnout and absenteeism. Psychology and Health, 16, 595-606.

Williams, K. J., \& Alliger, G. M. (1994). Role stressors, mood spillover, and perceptions of work-family conflict in employed parents. Academy of Management Journal, 37, 837-868.

Zapf, D. (1993). Stress-oriented analysis of computerized office work. European Work and Organizational Psychologist, 3, 85-100.

Zijlstra, F. R. H. (1996). Effort as energy regulation. In W. Battmann \& S. Dutke (Eds.), Processes of the molar regulation of behavior (pp. 219235). Lengerich, Germany: Pabst.

Zohar, D. (1999). When things go wrong: The effect of daily work hassles on effort, exertion and negative mood. Journal of Occupational and Organizational Psychology, 72, 265-283. 